\title{
BMJ Open The effect of community-acquired bacteraemia on return to workforce, risk of sick leave, permanent disability pension and death: a Danish population-based cohort study
}

\author{
Michael Dalager-Pedersen, ${ }^{1,2}$ Kristoffer Koch, ${ }^{2,3}$ Reimar Wernich Thomsen, ${ }^{2}$ \\ Henrik Carl Schønheyder, ${ }^{3}$ Henrik Nielsen ${ }^{1}$
}

To cite: Dalager-Pedersen $M$, Koch K, Wernich Thomsen R, et al. The effect of community-acquired bacteraemia on return to workforce, risk of sick leave, permanent disability pension and death: a Danish population-based cohort study. BMJ Open 2014;4: e004208. doi:10.1136/ bmjopen-2013-004208

- Prepublication history and additional material for this paper is available online. To view these files please visit the journal online (http://dx.doi.org/10.1136/ bmjopen-2013-004208).

Received 9 October 2013 Revised 13 December 2013 Accepted 9 January 2014

CrossMark

For numbered affiliations see end of article.

Correspondence to Dr Michael Dalager-Pedersen; midp@rn.dk

\section{ABSTRACT}

Objectives: Little is known about the prognosis of community-acquired bacteraemia (CAB) in workforce adults. We assessed return to workforce, risk for sick leave, disability pension and mortality within 1 year after $C A B$ in workforce adults compared with blood culture-negative controls and population controls.

Design: Population-based cohort study.

Setting: North Denmark, 1996-2011.

Participants: We used population-based healthcare registries to identify all patients aged 20-58 years who had first-time blood cultures obtained within $48 \mathrm{~h}$ of medical hospital admission, and who were part of the workforce (450 bacteraemia exposed patients and 6936 culture-negative control patients). For each bacteraemia patient, we included up to 10 matched population controls.

Primary and secondary outcome measures: Return to workforce, risk of sick leave, permanent disability pension and mortality within 1 year after bacteraemia. Regression analyses were used to compute adjusted relative risks (RRs) with $95 \%$ Cls. Results: One year after admission, $78 \%$ of patients with $\mathrm{CAB}, 85.7 \%$ of culture-negative controls and $96.8 \%$ of population controls were alive and in the workforce, and free from sick leave or disability pension. Compared with culture-negative controls bacteraemia was associated with an increased risk for long-term sick leave (4-week duration, $40.2 \%$ vs $23.9 \%$, adjusted RR, 1.51 ; Cl 1.34 to 1.70 ) and an increased risk for mortality (30-day mortality, $4 \%$ vs $1.4 \%$, adjusted RR, 2.34, Cl 1.22 to 4.50; 1-year mortality, $8 \%$ vs $3.9 \%$, adjusted RR, $1.73 ; \mathrm{Cl} 1.18$ to 2.55). Bacteraemia patients had a risk for disability pension similar to culture-negative controls $(2.7 \%$ vs $2.6 \%$, adjusted RR, 0.99 , Cl 0.48 to 2.02) but greater than population controls (adjusted RR, $5.20 ; 95 \% \mathrm{Cl}$ 2.16 to 12.50$)$.

Conclusions: $C A B$ is associated with long duration of sick leave and considerable mortality in working-age adults when compared with blood culture-negative controls, and an increased 1-year risk for disability pension when compared with population controls.

\section{Strengths and limitations of this study}

- To our knowledge, this is the first study to examine duration of sick leave and risk for permanent disability pension after communityacquired bacteraemia.

- Strengths include the population-based design and the use of highly valid prospectively collected data on bacteraemia, comorbidity and workforce affiliation.

- When comparing patients with community-acquired bacteraemia and controls, residual and unmeasured confounding may account for some of the increased risk for sick leave, disability pension and death.

\section{INTRODUCTION}

Hospitalisation for community-acquired bacteraemia $(\mathrm{CAB})$ has increased markedly in recent decades, and more than $30 \%$ of hospitalisations for $\mathrm{CAB}$ are in working-age adults. ${ }^{1}$

Overall, $\mathrm{CAB}$ is associated with a 30-day mortality of 13-20\% and a 1-year mortality of $25-45 \%,{ }^{2-6}$ with a lower mortality in working-age adults, for example, a 30-day mortality of $11-16 \%$ in 15-64-year-old patients. ${ }^{4-7}$ Apart from mortality, information is sparse on outcomes of bacteraemia in working-age adults. Only a few small cohort studies in hospitalised patients with infection have secondarily detailed the proportion of patients who returned to work, with conflicting results: $68 \%$ of patients with pneumonia may return to work within 30 days, ${ }^{8} 43 \%$ of survivors of septic shock within 1 year ${ }^{9}$ and $93 \%$ of survivors of severe sepsis within 3.5 years. ${ }^{10}$ None of these studies focused specifically on working-age patients, assessed risk for long-term sick leave or disability pension, accounted for retirement or 
included a comparison group. To our knowledge, no study has examined the prognosis after $\mathrm{CAB}$ in working-age adults who are part of the workforce and no study has examined return to work after CAB. Because $\mathrm{CAB}$ is increasingly common in working-age adults, it is important for patients, families and the society to have detailed knowledge on the prognosis in this age group.

We conducted a 15-year population-based cohort study among 20-58-year-old Danes who were part of the workforce, to examine return to work and risk for sick leave, permanent disability pension and mortality after medical hospitalisation with $\mathrm{CAB}$ in comparison with blood culture-negative controls and matched population controls.

\section{MATERIALS AND METHODS}

\section{Setting}

The study was conducted in healthcare region of North Denmark from 1996 to 2011. This area had a stable urban/rural catchment population of approximately 500000 inhabitants who received universal tax-financed primary and secondary care, free at the point of delivery. Throughout the study period, Aalborg University Hospital was the only referral hospital and all regional hospitals relied on its department of clinical microbiology for blood culture analyses.

For this study, we used prospectively collected data from seven Danish population-based registries. The Civil Registration System (CRS) ${ }^{11}$ which is updated daily, was used for personal data, including date of birth and death, place of residence and marital status. Unique CRS numbers, which are recorded for all healthcare contacts, and in administrative databases, facilitated linkage between registries. We further used data from the North Denmark Bacteraemia Research Database, ${ }^{12}$ the regional microbiology information system (ADBact; Autonik, Sköldinge, Sweden), ${ }^{4}$ the DREAM register on social transfer payments, ${ }^{13}$ the Aarhus University Prescription database ${ }^{14}$ and the regional Hospital Discharge Registry (HDR). ${ }^{15}$ Because data were acquired from registries which are generally available to Danish researchers, no informed consent was needed for this study.

\section{Data on blood cultures}

The bacteraemia database has registered all bacteraemia cases in the study area since 1981, prospectively since 1992. ${ }^{12}$ The microbiology information system has been used since 1995 and contains basic information on all blood cultures examined in the region. ${ }^{4}$ We used these databases for information on date of blood culture sampling, and also for information on infectious agent(s) and focus of infection in case of positive cultures. Throughout the study period, the blood culture system (BacT/Alert, bioMérieux, Marcy l'Etoil, France) was unchanged and is described in detail elsewhere. ${ }^{412}$

\section{Data on social transfers}

The DREAM database contains weekly information on social transfer benefits for all residents in Denmark who have received any such benefit, however, briefly, since $1991 .{ }^{13}{ }^{16}$ In Denmark, people who are part of the workforce (employed or unemployed) can receive sickness absence benefits (paid sick leave) during temporary illness. Paid sick leave is possible for a maximum of 52 weeks (with the possibility for extension) within an 18-month period. People whose illness causes a lasting reduced ability to work can receive permanent disability pension. During the study period, people who were in the workforce could go on early voluntary retirement when they turned 60 and optional retirement with public pension was possible from age 67 (1996-1999) or age 65 (2000-2011). For the present study, DREAM codes were categorised as work-ready codes (employed and unemployed), sick leave codes and permanent disability pension codes. DREAM codes are further detailed in online supplementary table S1. There is no universal definition of long-term sick leave; for this study and elsewhere, it is defined as a disease lasting at least four consecutive weeks. ${ }^{17}$

\section{Data on hospital admissions and comorbidity}

We used the HDR for data on hospital admissions and comorbidity. The HDR has recorded complete diagnosis codes from all inpatient hospitalisations in Denmark since 1977, and from outpatient clinic contacts since 1995. Diagnoses were coded by physicians according to the WHO's International Classification of Diseases (ICD)-8 until 1993 and ICD-10 thereafter).

We recorded the 19 disease categories in the Charlson Comorbidity Index (CCI) and alcohol-related disorders which we considered to be risk factors for death, sick leave and disability pension. ${ }^{18} 19$ The comorbidity level was categorised as low $(\mathrm{CCI}=0)$, medium $(\mathrm{CCI}=1-2)$ or high (CCI $>2$ ).

The Aarhus University Prescription database was used for information on preadmission medication use including disulfiram, antidiabetics, drugs for cardiovascular and pulmonary disease and systemic antibiotics. ${ }^{14}$ It contains Anatomical Therapeutic Chemical (ATC) classification code data on all reimbursed prescriptions since 1991. ICD and ATC codes used in this study are detailed in online supplementary table S2.

\section{Study subjects}

We included study participants who were $20-58$ years of age and were part of the workforce in the 4 weeks prior to admission, that is, did not receive permanent disability benefits, were not retired or on long-term sick leave (ie, received sickness absence benefits for a maximum of 3 weeks within 4 weeks prior to admission). Further eligibility criteria were no record of recent hospitalisation (previous 30 days), no previous blood culture draw (since 1995) or bacteraemia (since 1981) and residence within the study area for $\geq 1$ year. 
We identified all inpatients who had a first-time blood culture taken within $48 \mathrm{~h}$ of admission during 19962010. We defined $C A B$ as the presence of viable bacteria or fungi in the bloodstream, determined by blood cultures performed within $48 \mathrm{~h}$ of admission, among patients who were not admitted to the hospital within the previous 30 days. Study participants were categorised as patients with $\mathrm{CAB}$ or as blood culture-negative controls. Furthermore, for each patient with $\mathrm{CAB}$, we sampled 10 eligible population controls, who were alive on the date of hospital admission of the patient with $\mathrm{CAB}$ and with no recent hospitalisation, matched on sex and year of birth.

\section{Statistics}

We followed all study participants from the date of blood culture draw until death, emigration from Denmark or completion of 1 year of follow-up, whichever occurred first. We first computed the median number and IQR of weeks that patients were on paid sick leave during the year before and after blood culture draw. We then computed the risk of being on sick leave (receiving sickness absence benefits) for at least 4 and for 52 consecutive weeks, respectively, beginning in the week of blood culture draw. Log-binomial regression ${ }^{20}{ }^{21}$ was used to compute the risk difference (RD) and relative risk (RR) with $95 \%$ CI of 4-week and 52-week sick leave for patients with $\mathrm{CAB}$ versus culture-negative controls. In time-to-event analyses, we first constructed cumulative incidence curves for permanent disability pension and Kaplan-Meier curves for mortality. We used regression analyses based on pseudo-observations ${ }^{22}$ to compute RDs and RRs of permanent disability pension and mortality with $95 \%$ CIs for patients with $\mathrm{CAB}$ versus culture-negative controls and population controls. We considered death as a competing risk for permanent disability pension in all time-to-event analyses. In regression analyses, we adjusted for potential risk factors for sick leave, disability pension and death: age, gender, CCI score, alcoholism-related disease (including disulfiram use), medication use (antidiabetics, drugs for cardiovascular disease and pulmonary disease), civil status and immigrant status. ${ }^{3} 18 \quad 19$ 23-25 Because of few events among population controls, analyses concerning patients with $\mathrm{CAB}$ versus population controls were only adjusted for age and gender. In subgroup analyses, we examined the risk for long-term sick leave, disability pension and mortality according to etiological infectious agent and focus of infection. We also stratified analyses by gender, age group and employment status in the 4 weeks prior to admission. Because the management of $\mathrm{CAB}$ may have changed throughout the study period, we conducted up-to-date supplementary analyses pertaining to the latter half of the study period (2003-2011). Because previous antibiotic use could bias the risk estimates in our study when comparing patients with $\mathrm{CAB}$ and culture-negative controls, we conducted supplementary analyses in which we restricted to patients who had blood culture draw performed on admission and no recent out-of-hospital antibiotic use.

Stata V.11.2 for Windows (Stata Corp, College Station, Texas, USA) was used for all data analyses.

\section{RESULTS}

\section{Baseline characteristics}

We included 7386 acutely hospitalised patients who were part of the workforce immediately before hospitalisation and had a first-time blood culture drawn within $48 \mathrm{~h}$ of admission, 450 patients with $\mathrm{CAB}$ and 6936 controls with negative blood cultures. Patients with $\mathrm{CAB}$ were matched to 4500 population controls, of whom 3765 were included in the study (see flow diagram in the online supplement). Baseline characteristics for study participants can be found in table 1. Patients with $\mathrm{CAB}$ were older than culture-negative controls (median age in years 47.7 vs $41.4, \mathrm{p}<0.001$ ) but the burden of preexisting disease was similar and relatively low in both groups. Still, the disease burden was even lower among population controls. In the year before blood culture draw, study participants were on sick leave for a median of 0 weeks (IQR 0-1 week for patients with $\mathrm{CAB}$ and culture-negative controls, and $0-0$ for population controls).

\section{Return to work, duration of sickness leave} and disability pension

Exactly 1 year after blood culture draw 350 patients with CAB (78.0\%), 5944 culture-negative controls (85.7\%) and 3644 population controls $(96.8 \%)$ were alive and part of the workforce, and thus free from sick leave and disability pension (figure 1). In the year after blood culture draw, $50 \%$ of patients with $\mathrm{CAB}$ were on sick leave for at least 4 weeks (median 4, IQR 0-14 weeks) and $50 \%$ of culture-negative controls were on sick leave for 0 weeks (median 0 , IQR $0-7$ weeks). When compared with blood culture-negative controls, $\mathrm{CAB}$ was associated with an increased risk of sick leave for $\geq 4$ consecutive weeks $(40.2 \%$ vs $23.9 \%$, adjusted RR, $1.51 ; 95 \%$ CI 1.34 to 1.70$)$ and $\geq 52$ weeks $(5.8 \%$ vs $2.6 \%$, adjusted RR, 1.96; $95 \%$ CI 1.31 to 2.93; table 2). However, the 1-year risk for disability pension was similar in the two groups, $2.7 \%$ for patients with $\mathrm{CAB}$ and $2.6 \%$ for culture-negative controls (adjusted RR, 0.99; 95\% CI 0.48 to 2.02), see table 2 and figure 2. When compared with population controls, $\mathrm{CAB}$ was associated with an increased risk for 1-year disability pension $(2.7 \%$ vs $0.6 \%$, adjusted RR, $5.20 ; 95 \%$ CI 2.16 to 12.50$)$.

\section{Mortality}

Mortality rose sharply to $4 \%$ for patients with $\mathrm{CAB}$ within the first 30 days (see online supplementary figure S2), $1.4 \%$ for culture-negative controls (adjusted RR, 1.87; 95\% CI 1.03 to 3.40 ; table 2) and 0 for population controls. Within 1 year the mortality was $8.0 \%$ for patients with $\mathrm{CAB}, 3.9 \%$ for culture-negative controls (adjusted 
Table 1 Descriptive characteristics of workforce community-acquired bacteraemia patients and blood culture-negative controls, North Denmark, 1996-2010

\begin{tabular}{|c|c|c|c|}
\hline & $\begin{array}{l}\text { Patients with CAB } \\
(n=450)\end{array}$ & $\begin{array}{l}\text { Blood culture-negative patients } \\
(n=6936)\end{array}$ & $\begin{array}{l}\text { Population controls } \\
(n=3765)\end{array}$ \\
\hline \multicolumn{4}{|l|}{ Age, years } \\
\hline 20-34 & $85(18.9)$ & $2338(33.7)$ & 767 (20.4) \\
\hline $35-49$ & $178(39.6)$ & 2676 (38.6) & 1554 (41.3) \\
\hline $50-58$ & $187(41.6)$ & $2693(27.7)$ & 1444 (38.3) \\
\hline \multicolumn{4}{|l|}{ Gender } \\
\hline Female & $224(49.8)$ & $3100(44.7)$ & $1851(49.2)$ \\
\hline Male & $226(50.2)$ & 3836 (55.3) & $1914(50.8)$ \\
\hline \multicolumn{4}{|l|}{ Marital status } \\
\hline Married & $261(58.0)$ & $3592(51.8)$ & $2311(61.4)$ \\
\hline Never married or unknown* & $129(28.7)$ & 2521 (36.3) & $982(26.1)$ \\
\hline Divorced or widowed & 60 (13.3) & 823 (11.9) & $472(12.5)$ \\
\hline \multicolumn{4}{|l|}{ Immigrant status } \\
\hline Native Dane† & $429(95.3)$ & $6520(94.0)$ & 3536 (93.9) \\
\hline Immigrant & $21(4.7)$ & $416(6.0)$ & $229(6.1)$ \\
\hline \multicolumn{4}{|l|}{ Comorbidity, any previous $\ddagger$} \\
\hline Myocardial infarction & $4(0.9)$ & $76(1.1)$ & $19(0.5)$ \\
\hline Congestive heart failure & $1(0.2)$ & $22(0.3)$ & $3(0.1)$ \\
\hline Peripheral vascular disease & $5(1.1)$ & $55(0.8)$ & $18(0.5)$ \\
\hline Cerebrovascular disease & $8(1.8)$ & $85(1.2)$ & $29(0.8)$ \\
\hline Hemiplegia & $0(0)$ & $6(0.1)$ & $2(0.1)$ \\
\hline Chronic pulmonary disease & $24(5.3)$ & $523(7.5)$ & $102(2.7)$ \\
\hline Diabetes mellitus & $26(5.8)$ & $276(4.0)$ & $36(1.0)$ \\
\hline Diabetes with end-organ & $10(2.2)$ & $133(1.9)$ & $7(0.2)$ \\
\hline \multicolumn{4}{|l|}{ damage } \\
\hline Connective tissue disease & $9(2.0)$ & $118(1.7)$ & $29(0.8)$ \\
\hline Moderate to severe renal & $3(0.7)$ & $93(1.3)$ & $15(0.4)$ \\
\hline \multicolumn{4}{|l|}{ disease } \\
\hline Peptic ulcer disease & $8(1.8)$ & $122(1.8)$ & $48(1.3)$ \\
\hline Mild liver disease & $6(1.3)$ & $80(1.2)$ & $10(0.3)$ \\
\hline Moderate to severe liver disease & $4(0.9)$ & $17(0.3)$ & $3(0.1)$ \\
\hline Any tumour & $15(3.3)$ & $193(2.8)$ & $65(1.7)$ \\
\hline Leukaemia & $1(0.2)$ & $25(0.4)$ & $3(0.1)$ \\
\hline Lymphoma & $0(0)$ & $24(0.4)$ & $1(0.0)$ \\
\hline Metastatic solid tumour & $2(0.4)$ & $19(0.3)$ & $6(0.2)$ \\
\hline Dementia & $0(0)$ & $1(0.0)$ & $0(0)$ \\
\hline HIVIAIDS & $3(0.7)$ & $11(0.2)$ & $1(0.0)$ \\
\hline Alcoholism-related disease & $33(7.3)$ & $428(6.2)$ & $95(2.5)$ \\
\hline \multicolumn{4}{|l|}{ Medication use, any previous } \\
\hline $\begin{array}{l}\text { Drugs for cardiovascular } \\
\text { disease }\end{array}$ & $120(26.7)$ & $1741(25.1)$ & $579(15.4)$ \\
\hline Inhalers for pulmonary disease & $119(26.4)$ & 2104 (30.3) & $1159(30.8)$ \\
\hline Antidiabetics & $35(7.8)$ & $375(5.4)$ & $51(1.4)$ \\
\hline Disulfiram & $19(4.2)$ & $202(2.9)$ & $25(0.7)$ \\
\hline Antibiotics (past 4 weeks) & 74 (16.4) & $2031(29.3)$ & $83(2.2)$ \\
\hline \multicolumn{4}{|l|}{ Charlson Comorbidity Index $\ddagger$} \\
\hline 0 & $357(79.3)$ & $5468(78.8)$ & 3414 (90.7) \\
\hline $1-2$ & $87(19.3)$ & $1403(20.2)$ & $347(9.2)$ \\
\hline$>2$ & $6(1.3)$ & $65(0.9)$ & $4(0.1)$ \\
\hline \multicolumn{4}{|l|}{ Employment status } \\
\hline Employed, past 4 weeks§ & $281(62.4)$ & $4624(66.7)$ & 3166 (84.1) \\
\hline Unemployed, past 4 weeks & $107(23.8)$ & $1384(20.0)$ & $538(13.8)$ \\
\hline Sick leave, past 4 weeks ${ }^{\star *}$ & $62(13.8)$ & $928(13.4)$ & $61(1.6)$ \\
\hline 1 week & $43(9.6)$ & $605(8.7)$ & $35(0.9)$ \\
\hline 2 weeks & $11(2.4)$ & 231 (3.3) & $17(0.5)$ \\
\hline 3 weeks & $8(1.8)$ & $92(1.3)$ & $9(0.2)$ \\
\hline
\end{tabular}

*Unknown for $0.7 \%$.

†Includes $0.18 \%$ children of first-generation immigrants.

$\ddagger$ Based on ICD-codes that are detailed in the online supplement.

$\S$ Participants who were registered as employed and actively working during all 4 weeks before admission.

ๆParticipants who spent all 4 weeks as unemployed and participants who were employed/unemployed.

${ }^{* *}$ Participants who were on sick leave for a maximum of 3 weeks in the previous 4 weeks, and otherwise employed or unemployed.

$\mathrm{CAB}$, community-acquired bacteraemia; ICD, International Classification of Diseases. 


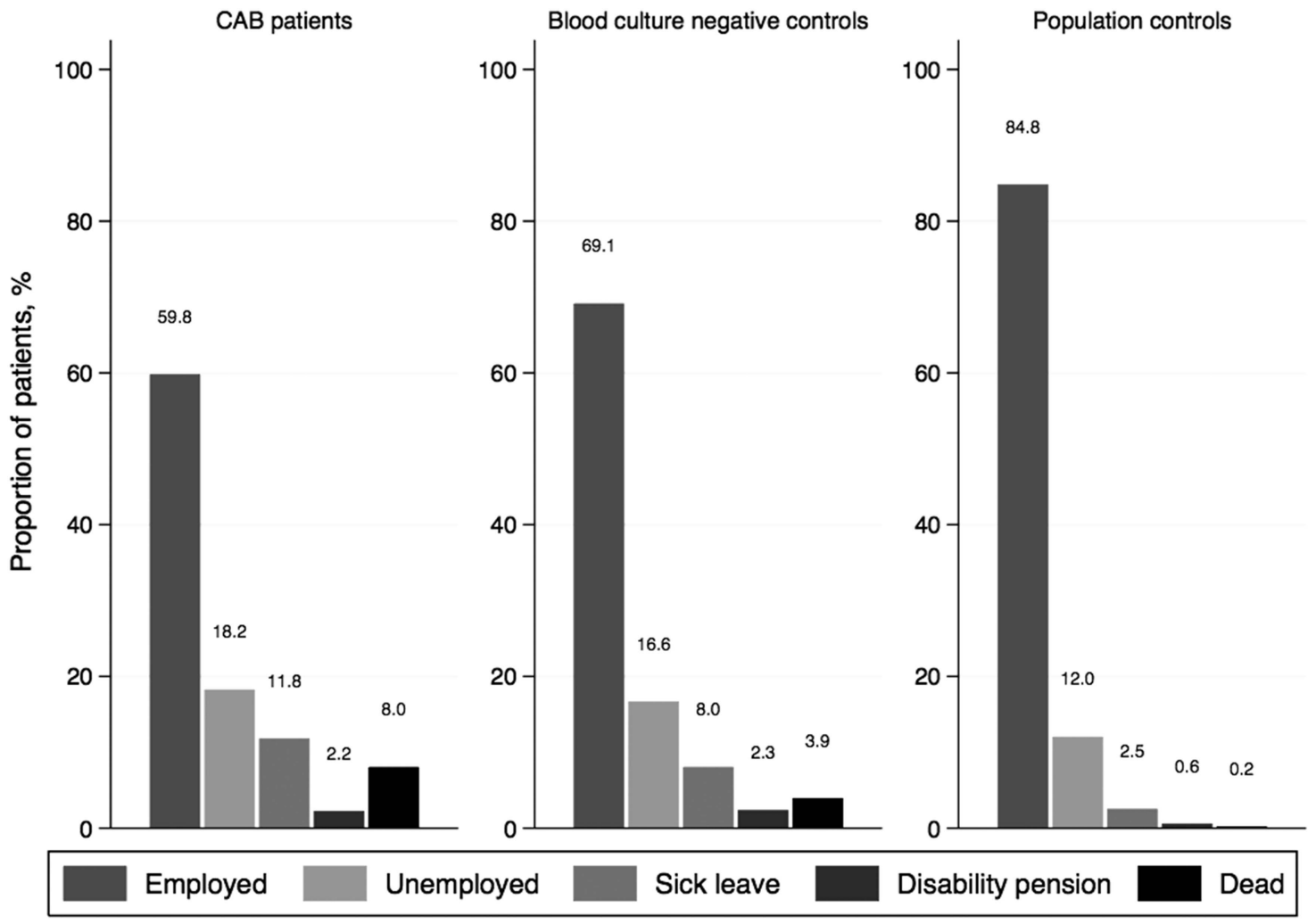

Figure 1 Employment status and mortality at 1 year after blood culture draw. Note, the cumulative incidence of sick leave and disability pension within 1 year is higher than the proportion of patients that received either benefit at 1 year after blood culture draw (eg, some patients went on sick leave or became disability pensioners and later died during 1 year of follow-up).

RR, 1.52; $95 \%$ CI 1.10 to 2.10; table 2) and $0.2 \%$ for population controls (adjusted RR, 37.83; 95\% CI 15.67 to 91.29).

\section{Subgroup and stratified analyses}

Subgroups of patients with pneumococcal or other Gram-positive infection had a higher risk for 4-week sick leave, 52-week sick leave and 1-year disability pension after $\mathrm{CAB}$ than patients with Escherichia coli infection or other Gram-negative infection (table 3). Of note, pneumococcal infection was associated with the lowest level of comorbidity ( $85 \%$ with CCI score of 0$)$, the lowest 30-day (1.7\%) and 1-year mortality $(4.5 \%)$ and the highest 1-year risk for permanent disability pension

Table 2 Sick leave, disability pension and mortality among patients with $C A B(N=450)$ and blood culture-negative controls $(\mathrm{N}=6936)$

\begin{tabular}{|c|c|c|c|c|c|c|c|}
\hline & & \multicolumn{2}{|c|}{$\begin{array}{l}\text { Risk number of events } \\
(\% \text { of } N)\end{array}$} & \multicolumn{2}{|c|}{ Risk difference, \% (95\% Cl) } & \multicolumn{2}{|c|}{ Relative risk (95\% CI) } \\
\hline & & $\begin{array}{l}\text { patients } \\
\text { with CAB }\end{array}$ & Controls & Crude & Adjusted & Crude & Adjusted \\
\hline \multirow{2}{*}{$\begin{array}{l}\text { Sick } \\
\text { leave* }\end{array}$} & $\geq 4$ weeks & $181(40.2)$ & $1658(23.9)$ & 16.3 (11.7 to 21.0$)$ & 14.1 (9.5 to 18.7$)$ & $1.68(1.49$ to 1.90$)$ & 1.51 (1.34 to 1.70$)$ \\
\hline & $\geq 52$ weeks & $26(5.8)$ & $181(2.6)$ & $3.2(1.0$ to 5.4$)$ & $3.0(0.8$ to 5.2$)$ & 2.21 (1.48 to 3.30$)$ & 1.96 (1.31 to 2.93$)$ \\
\hline $\begin{array}{l}\text { Disability } \\
\text { pension }\end{array}$ & 1 year & $12(2.7)$ & $183(2.6)$ & $0.0(-1.5$ to 1.6$)$ & $-0.5(-2.1$ to 1.0$)$ & $1.01(0.57$ to 1.80$)$ & 0.99 (0.48 to 2.02) \\
\hline \multirow{2}{*}{ Mortality } & 30 days & $18(4.0)$ & $99(1.4)$ & $2.6(0.7$ to 4.4$)$ & $2.2(0.4$ to 4.0$)$ & 2.80 (1.71 to 4.59$)$ & 2.34 (1.22 to 4.50$)$ \\
\hline & 1 year & $36(8.0)$ & 271 (3.9) & 4.1 (1.5 to 6.6$)$ & $3.1(0.6$ to 5.6$)$ & 2.05 (1.47 to 2.86$)$ & 1.73 (1.18 to 2.55$)$ \\
\hline
\end{tabular}




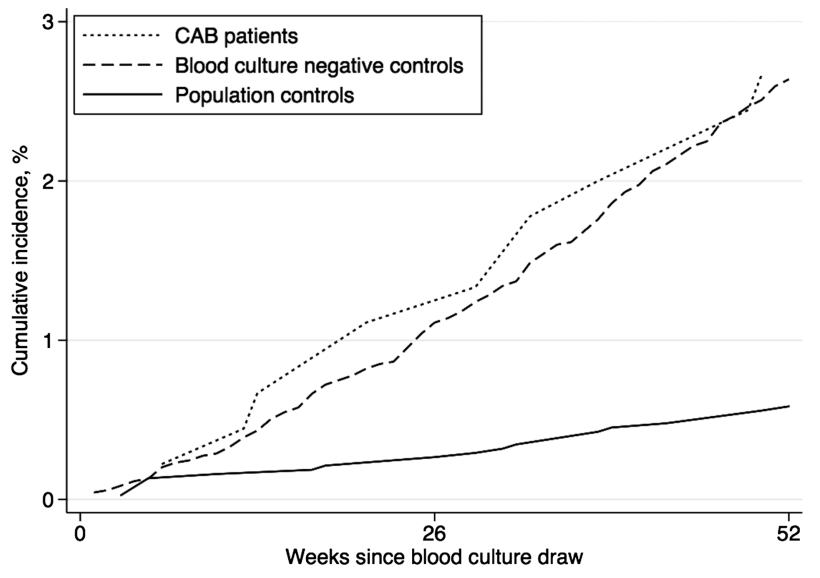

Figure 2 Cumulative incidence of permanent disability pension in workforce patients with community-acquired bacteraemia (CAB), blood culture-negative controls, and population controls in North Denmark, 1996-2011.

(3.4\%; table 3). Patients with Staphylococcus aureus bacteraemia and polymicrobial bacteraemia had the highest levels of comorbidity $(71 \%$ with CCI score of 0 in both groups) and also had the highest 30-day mortality $(S$ aureus, 3/31, 9.7\% and polymicrobial CAB, 3/14, 21.4\%) and 1-year mortality ( $S$ aureus, $5 / 31,16.1 \%$ and polymicrobial CAB, 4/14, 28.6\%). In these small subgroups with high mortality, a high proportion of patients were on sick leave for a long time after infection (eg, 6/31, 19.4\% of patients with $S$ aureus infection were on sick leave for 52 consecutive weeks) but the 1-year risk for disability pension was 0 . Irrespective of type of focus, $\mathrm{CAB}$ was associated with an increased risk for long-term sick leave when compared with culture-negative controls (eg, $40.2 \%$ of patients with $\mathrm{CAB}$ with respiratory tract infection were on sick leave for at least 4 weeks, adjusted RR, $1.51 ; 95 \%$ CI 1.26 to 1.83$)$. Mortality was particularly high among patients with an unknown focus or more than one focus of infection (30-day mortality of $14.3 \%$ ), see online supplementary table S3.

When stratifying analyses according to age group and employment status, older age and unemployment were associated with the highest absolute risks for disability pension and mortality (see online supplementary table S4). When comparing patients with $\mathrm{CAB}$ to blood culturenegative controls in stratified analyses, $\mathrm{CAB}$ was consistently associated with an increased risk for 4-week sick leave, 52-week sick leave and for 30-day and 1-year mortality, table 4 in supplementary $\mathrm{S} 4$.

During 2003 to 2011, the association between CAB and study outcomes remained essentially unchanged when compared with culture-negative controls (4-week sick leave $37.7 \%$ vs $23.6 \%$, adjusted RR, $1.40 ; 95 \%$ CI 1.18 to 1.66 ; 1-year disability pension $3.4 \%$ vs $2.4 \%$, adjusted RR, 1.58; $95 \%$ CI 0.54 to 4.59 ; 30-day mortality $3.0 \%$ vs $1.1 \%$, adjusted RR, 2.09; $95 \%$ CI 0.76 to 5.70 and 1-year mortality $7.6 \%$ vs $3.3 \%$, adjusted RR, 2.14; $95 \%$ CI 1.29 to 3.52 ).
Analyses restricted to 352 patients with $\mathrm{CAB}$ and 4078 culture-negative controls who had no previous antibiotic therapy (blood culture draw performed on admission and no recent out-of-hospital antibiotic use) did not materially influence the association between $\mathrm{CAB}$ and 4-week sick leave (adjusted RR, 1.71; 95\% CI 1.48 to 1.97), 1-year disability pension (adjusted RR, 1.00; $95 \%$ CI 0.06 to 16.82 ), 30-day mortality (adjusted RR, 1.73; $95 \%$ CI 0.68 to 4.41 ) or 1-year mortality (adjusted RR, $1.70 ; 95 \%$ CI 1.02 to 2.84$)$.

\section{DISCUSSION}

In this large population-based cohort study of adults in the Danish workforce, we found that $\mathrm{CAB}$ was associated with a $40 \%$ risk for sick leave of at least 4 weeks duration and a nearly $6 \%$ risk for 52 weeks of sick leave. Compared with blood culture-negative controls, CAB increased the risk for long-term sick leave by 50-100\% but the risk for permanent disability pension within 1 year was similar $(\sim 2.7 \%)$. Compared with population controls, $\mathrm{CAB}$ was associated with a fivefold increased risk for disability pension. While $\mathrm{CAB}$ more than doubled the 30-day risk for death and remained associated with a $70 \%$ increased risk for death within 1 year when compared with culture-negative controls, the absolute mortality was low after $\mathrm{CAB}$ in this study $4 \%$ within 30 days and $8 \%$ within 1 year). One year after the blood culture draw, nearly $80 \%$ of patients with $\mathrm{CAB}$ were back in the workforce.

We are not aware of any study that has examined duration of sick leave and risk for permanent disability pension after CAB. Very few previous studies have examined return to work after severe bacterial infection, and in most of these studies this outcome has been a secondary focus and examined in small subgroups of included patients. Poulsen et a ${ }^{9}$ conducted a study of 172 Danish intensive care unit (ICU) patients with septic shock, and examined physical outcomes in a subgroup of 70 of 80 1-year survivors. At 1-year follow-up, $43 \%$ (10/23) of previously employed patients had returned to work, which is considerably fewer than the approximately $80 \%$ of patients with $\mathrm{CAB}$ who were in the workforce after 1 year in our study. The discrepancy may relate to ICU patients with septic shock being more critically ill than average patients with $\mathrm{CAB}$ and it may be related to older study participants in the ICU-based study who may have had the possibility of public retirement pension during the follow-up. In a study from Scotland, Cuthbertson et $a l^{10}$ followed 439 ICU patients with sepsis and asked employment-related questions to survivors at 3.5 and 5 years. At 3.5 years, 93\% (53/62 respondents) of previously employed patients had returned to work, and at 5 years the proportion was $75 \%$ (46/58 respondents) with some reduction in employment due to retirement.

Return to work after community-acquired pneumonia has been described by Fine et $a l^{8}$ who followed 2287 patients for 30 days, including 539 previously employed 
Table 3 Risk for sick leave, permanent disability pension and mortality in CAB by aetiological agent compared with blood culture-negative controls

\begin{tabular}{|c|c|c|c|c|c|}
\hline & $\begin{array}{l}\text { Streptococcus } \\
\text { pneumoniae } \\
(\mathrm{N}=177)\end{array}$ & $\begin{array}{l}\text { Other } \\
\text { Gram-positive } \\
(\mathrm{N}=78)\end{array}$ & $\begin{array}{l}\text { Escherichia coli } \\
(\mathrm{N}=103)\end{array}$ & $\begin{array}{l}\text { Other } \\
\text { Gram-negative } \\
(\mathrm{N}=78)\end{array}$ & $\begin{array}{l}\text { Polymicrobial } \\
(\mathrm{N}=14)\end{array}$ \\
\hline \multicolumn{6}{|l|}{ Sick leave, $\geq 4$ weeks } \\
\hline Risk, $n$ (\% of $\mathrm{N})$ & $75(42.4)$ & $44(56.4)$ & $30(29.1)$ & $30(38.5)$ & $2(14.3)$ \\
\hline Adj. RD \% $(95 \% \mathrm{CI})^{*}$ & 15.3 (8.0 to 22.6$)$ & 30.1 (19.2 to 41.1$)$ & $3.5(-5.2$ to 12.2$)$ & $12.8(2.1$ to 23.5$)$ & $-6.4(-24.3$ to 11.5$)$ \\
\hline Adj. RR $(95 \% \mathrm{Cl})^{\star}$ & 1.57 (1.32 to 1.87$)$ & 2.03 (1.66 to 2.49$)$ & $1.14(0.84$ to 1.54$)$ & 1.46 (1.10 to 1.93$)$ & $0.55(0.15$ to 2.03$)$ \\
\hline \multicolumn{6}{|l|}{ Sick leave, $\geq 52$ weeks } \\
\hline Risk, $\mathrm{n}(\%$ of $\mathrm{N})$ & $9(5.1)$ & $11(14.1)$ & $2(1.9)$ & $3(3.8)$ & $1(7.1)$ \\
\hline Adj. RD \% $(95 \% \mathrm{CI})^{*}$ & $1.9(-1.3$ to 5.0$)$ & 11.5 (3.7 to 19.3$)$ & $-1.2(-1.8$ to -0.1$)$ & $1.3(-3.0$ to 5.6$)$ & $5.9(-8.7$ to 20.4$)$ \\
\hline Adj. RR $(95 \% \mathrm{Cl})^{\star}$ & $1.73(0.90$ to 3.33$)$ & 4.65 (2.62 to 8.24$)$ & $0.64(0.16$ to 2.56$)$ & $1.33(0.44$ to 4.07$)$ & $2.49(0.36$ to 17.29$)$ \\
\hline \multicolumn{6}{|c|}{ Disability pension, 1 year } \\
\hline Risk, $\mathrm{n}(\%$ of $\mathrm{N})$ & $6(3.4)$ & $2(2.6)$ & $2(1.9)$ & $2(2.6)$ & $0(0)$ \\
\hline Adj. RD \% $(95 \% \mathrm{Cl})^{\star}$ & $0.5(-2.2$ to 3.1$)$ & $-0.8(-4.3$ to 2.6$)$ & $-1.7(4.5$ to 1.0$)$ & $-0.5(-3.9$ to 2.9$)$ & $-3.1(-4.7$ to -1.5$)$ \\
\hline Adj. RR $(95 \% \mathrm{Cl})^{\star}$ & $1.63(0.66$ to 4.05$)$ & $0.79(0.18$ to 3.54$)$ & $0.35(0.07$ to 4.75$)$ & $1.19(0.30$ to 4.75$)$ & - \\
\hline \multicolumn{6}{|l|}{ Mortality, 30 days } \\
\hline Risk, $n(\%$ of $N)$ & $3(1.7)$ & $5(6.4)$ & $5(4.9)$ & $2(2.6)$ & $3(21.4)$ \\
\hline Adj. RD \% $(95 \% \mathrm{Cl})^{*}$ & $-0.1(-2.1$ to 1.8$)$ & $4.6(-0.8$ to 10.0$)$ & $3.0(-1.2$ to 7.2$)$ & $0.8(-2.6$ to 4.3$)$ & $20.0(-1.5$ to 41.5$)$ \\
\hline Adj. RR $(95 \% \mathrm{Cl})^{\star}$ & 1.05 (0.30 to 3.67$)$ & $3.82(1.49$ to 9.81$)$ & $1.90(0.55$ to 6.61$)$ & $1.81(0.45$ to 7.34$)$ & 13.97 (3.26 to 59.86$)$ \\
\hline \multicolumn{6}{|l|}{ Mortality, 1 year } \\
\hline Risk, n (\% of $\mathrm{N})$ & $8(4.5)$ & $12(15.4)$ & $9(8.7)$ & $3(3.8)$ & $4(28.6)$ \\
\hline Adj. RD \% $(95 \% \mathrm{Cl})^{*}$ & $-0.1(-3.2$ to 3.0$)$ & 10.1 (2.4 to 17.8$)$ & $3.6(-1.6$ to 8.7$)$ & $-0.8(-5.0$ to 3.5$)$ & $23.8(-0.4$ to 48.0$)$ \\
\hline Adj. RR $(95 \% \mathrm{Cl})^{*}$ & 0.81 (0.36 to 1.81$)$ & 3.46 (2.22 to 5.38$)$ & 1.97 (1.04 to 3.73$)$ & 0.67 (0.19 to 2.35$)$ & $3.55(0.78$ to 16.10$)$ \\
\hline
\end{tabular}

outpatients and 218 previously employed inpatients. Among less sick outpatients, nearly all (95.3\%) of the previously employed had returned to work at day 30. In contrast, $68.1 \%$ of previously employed inpatients had returned to work at day 30 and the median time to return to work was 22 days, which is comparable with our findings of a median of 4 weeks on sick leave after CAB.

This is also the first study to examine the mortality after $\mathrm{CAB}$ in relatively healthy adults who belong to the workforce immediately before onset of CAB. Some previous cohort studies have examined mortality after CAB according to age group. Søgaard $e t a \hat{l}$ found a 30-day mortality of $11 \%$ in 15-64-year-old patients with $\mathrm{CAB}$, and Leibovici et $a \bar{l}$ found a 1-year mortality of $29 \%$ after bacteraemia in patients with 18-60 years of age. In a Danish population-based cohort study of 8653 bacteraemia patients aged 30-65 years, Koch et al examined mortality according to socioeconomic status and found the highest 30-day mortality $(19.7 \%)$ in the subgroup with most disability pensioners (the lowest income group). As we excluded nearly $30 \%$ of $20-58$-year-old patients with $\mathrm{CAB}$ because of disability pension or sick leave, the higher short-term and long-term mortality described in previous studies is likely due to the inclusion of multimorbid patients outside the workforce. Our study supports previous studies that have examined the economic costs of sepsis and bacteraemia and found that the indirect costs (productivity loss due to mortality, temporary and permanent morbidity) may outweigh the direct costs (eg, medical expenses associated with hospitalisation) by as much as twofold, and that these severe infections place a high economic burden on individuals, families and the society. ${ }^{26} 27$

Physical and psychological stress is put on hospitalised patients with $\mathrm{CAB}$, and may endure beyond the duration of hospitalisation. In surviving working-age patients, this may lead to prolonged sick leave or permanent disability. During hospitalisation, patients with severe infections are at risk for complications, including some that may be long-lasting/permanent (eg, renal impairment and cardiovascular disease). ${ }^{28} 29$ Patients with severe infections may occasionally have abnormal vital signs and ongoing inflammatory activity at discharge. ${ }^{30}$ After discharge, they remain at high risk for mortality and for other diseases such as cardiovascular events, and may experience worsened cognitive status and quality of life. ${ }^{29} 31-33$

This study has several strengths. It is large, including more than 10000 study participants, and it has complete and long follow-up of all study participants. Moreover, data were obtained from high-quality databases, in which they were prospectively recorded, which limits recall bias.

However, this study also has limitations. Sick leave of short duration is under-reported to the social services in 
Denmark and we may, therefore, underestimate the true duration of sick leave in hospitalised participants, especially the lower quartile values of sick leave ( 0 weeks in both groups). However, data on sick leave of at least 15 days duration have been found to be highly valid. ${ }^{34}$ Another limitation is that Danes in their late 50s who have declining health may wait for voluntary early retirement instead of applying for disability pension. ${ }^{35}$ Since patients with $\mathrm{CAB}$ were older than controls, this could lead to falsely increased risk estimates for long-term sick leave and falsely decreased risk estimates for disability pension. In analyses of mortality by focus of infection, immortal-time bias may have prompted falsely low risks of death in patients with an identified focus of infection (and a high risk of death in patients with an unknown focus). Moreover, although we adjusted for many potential confounders, residual and unmeasured confounding is a possibility. Finally, findings from the present study may not directly apply to other countries with dissimilar laws and regulations regarding the job market and social benefits.

In conclusion, our study highlights that $\mathrm{CAB}$ is a debilitating condition in adults who are part of the workforce. $\mathrm{CAB}$ is associated with long duration of sick leave, but in this relatively healthy population, a low risk for permanent disability and death.

\section{Author affiliations \\ ${ }^{1}$ Department of Infectious Diseases, Aalborg University Hospital, Aalborg, Denmark \\ ${ }^{2}$ Department of Clinical Epidemiology, Institute of Clinical Medicine, Aarhus University Hospital, Aarhus N, Denmark \\ ${ }^{3}$ Department of Clinical Microbiology, Aalborg University Hospital, Aalborg, Denmark}

Acknowledgements The authors would like to thank Mrs Lena Mortensen, Department of Clinical Microbiology, Aalborg University Hospital, for meticulous assistance with the North Denmark Bacteraemia Research Database. They also thank Rikke Mortensen, Department of Clinical Epidemiology, Aarhus University Hospital, for helping with data preparation.

Contributors MD-P, KK, RWT, HCS and HN made substantial contributions to study conception and design, interpreted the data and critically revised the manuscript. MDP, RWT and HCS were responsible for acquisition of data. MDP analysed the data and drafted the manuscript. All authors approved the final version of the manuscript.

Funding This work was supported by the Karen Elise Jensen, Heinrich Kopp, Svend Andersen, and Helga and Peter Korning Foundations, and the North Denmark Health Sciences Research Foundation.

Competing interests None.

Ethics approval The study was approved by the Danish Data Protection Agency (2011-41-5864).

Provenance and peer review Not commissioned; externally peer reviewed.

Data sharing statement No additional data are available.

Open Access This is an Open Access article distributed in accordance with the Creative Commons Attribution Non Commercial (CC BY-NC 3.0) license, which permits others to distribute, remix, adapt, build upon this work noncommercially, and license their derivative works on different terms, provided the original work is properly cited and the use is non-commercial. See: http:// creativecommons.org/licenses/by-nc/3.0/

\section{REFERENCES}

1. Søgaard M, Nørgaard M, Dethlefsen C, et al. Temporal changes in the incidence and 30-day mortality associated with bacteremia in hospitalized patients from 1992 through 2006: a population-based cohort study. Clin Infect Dis 2011;52:61-9.

2. Bearman GML, Wenzel RP. Bacteremias: a leading cause of death. Arch Med Res 2005;36:646-59.

3. Søgaard M, Schønheyder HC, Riis A, et al. Short-term mortality in relation to age and comorbidity in older adults with community-acquired bacteremia: a population-based cohort study. $J$ Am Geriatr Soc 2008;56:1593-600.

4. Søgaard M, Nørgaard M, Pedersen L, et al. Blood culture status and mortality among patients with suspected community-acquired bacteremia: a population-based cohort study. BMC Infect Dis 2011;11:139.

5. Leibovici L, Samra Z, Konigsberger H, et al. Long-term survival following bacteremia or fungemia. JAMA 1995;274:807-12.

6. Laupland KB, Svenson LW, Gregson DB, et al. Long-term mortality associated with community-onset bloodstream infection. Infection 2011;39:405-10.

7. Koch K, Nørgaard M, Schønheyder HC, et al. Effect of socioeconomic status on mortality after bacteremia in working-age patients. A Danish population-based cohort study. PLOS ONE 2013;8:e70082.

8. Fine MJ, Stone RA, Singer DE, et al. Processes and outcomes of care for patients with community-acquired pneumonia: results from the Pneumonia Patient Outcomes Research Team (PORT) cohort study. Arch Intern Med 1999;159:970-80.

9. Poulsen JB, Møller K, Kehlet H, et al. Long-term physical outcome in patients with septic shock. Acta Anaesthesiol Scand 2009; 53:724-30.

10. Cuthbertson BH, Elders A, Hall S, et al. Mortality and quality of life in the five years after severe sepsis. Crit Care 2013;17:R70.

11. Pedersen CB. The Danish Civil Registration System. Scand J Public Health 2011;39:22-5.

12. Schønheyder HC, Søgaard M. Existing data sources for clinical epidemiology: the North Denmark Bacteremia Research Database. Clin Epidemiol 2010;2:171-8.

13. Lund T, Labriola M, Christensen KB, et al. Physical work environment risk factors for long term sickness absence: prospective findings among a cohort of 5357 employees in Denmark. BMJ 2006;332:449-52.

14. Ehrenstein V, Antonsen S, Pedersen L. Existing data sources for clinical epidemiology: Aarhus University Prescription Database. Clin Epidemiol 2010;2:273-9.

15. Lynge E, Sandegaard JL, Rebolj M. The Danish National Patient Register. Scand J Public Health 2011;39:30-3.

16. Hjollund $\mathrm{NH}$, Larsen $\mathrm{FB}$, Andersen $\mathrm{JH}$. Register-based follow-up of social benefits and other transfer payments: accuracy and degree of completeness in a Danish interdepartmental administrative database compared with a population-based survey. Scand J Public Health 2007;35:497-502.

17. National Institute for Health and Clinical Excellence. Long-term sickness absence and incapacity for work. 2009. http://www.nice. org.uk/ph19 (accessed 8 Oct 2013).

18. Sidorchuk A, Hemmingsson T, Romelsjö A, et al. Alcohol use in adolescence and risk of disability pension: a 39 year follow-up of a population-based conscription survey. PLOS ONE 2012;7:e42083.

19. Charlson ME, Pompei $\mathrm{P}$, Ales KL, et al. A new method of classifying prognostic comorbidity in longitudinal studies: development and validation. J Chronic Dis 1987;40:373-83.

20. Cummings $P$. Methods for estimating adjusted risk ratios. Stata $J$ 2009:9:175-96. http://www.stata-journal.com/article.html? article=st0162 (accessed 19 Aug 2013).

21. Cummings $P$. Estimating adjusted risk ratios for matched and unmatched data: an update. Stata J 2011;11:290-8. http://www. stata-journal.com/article.html?article=st0162_1 (accessed 8 Oct 2013).

22. Parner E, Andersen P. Regression analysis of censored data using pseudo-observations. Stata J 2010;10:408-22. http://www. stata-journal.com/article.html?article=st0202 (accessed 11 May 2013).

23. Johansson $\mathrm{B}$, Helgesson $\mathrm{M}$, Lundberg I, et al. Work and health among immigrants and native Swedes 1990-2008: a register-based study on hospitalization for common potentially work-related disorders, disability pension and mortality. BMC Public Health 2012;12:845.

24. Seymour CW, Iwashyna TJ, Cooke CR, et al. Marital status and the epidemiology and outcomes of sepsis. Chest 2010;137:1289-96.

25. Beskæftigelsesministeriet [Ministry of Employment]. Analyse af sygefraværet [Analysis of sickness absence]. 2008. http://bm.dk/ 
/media/BEM/Files/Dokumenter/Publikationer/2008/Sygefravaer. ashx (accessed 8 Oct 2013).

26. Chalupka AN, Talmor D. The economics of sepsis. Crit Care Clin 2012;28:57-76, vi.

27. Schmid A, Burchardi $\mathrm{H}$, Clouth $\mathrm{J}$, et al. Burden of illness imposed by severe sepsis in Germany. Eur J Health Econ 2002;3:77-82.

28. Mackenzie I, Lever A. Management of sepsis. BMJ 2007;335:929-32.

29. Corrales-Medina VF, Madjid M, Musher DM. Role of acute infection in triggering acute coronary syndromes. Lancet Infect Dis 2010;10:83-92

30. Yende S, D'Angelo G, Kellum JA, et al. Inflammatory markers at hospital discharge predict subsequent mortality after pneumonia and sepsis. Am J Respir Crit Care Med 2008;177:1242-7.

31. Leibovici L. Long-term consequences of severe infections. Clin Microbiol Infect 2013;19:510-12.
32. Winters BD, Eberlein M, Leung J, et al. Long-term mortality and quality of life in sepsis: a systematic review. Crit Care Med 2010;38:1276-83.

33. Semmler A, Widmann CN, Okulla T, et al. Persistent cognitive impairment, hippocampal atrophy and EEG changes in sepsis survivors. J Neurol Neurosurg Psychiatry 2013;84:62-9.

34. Stapelfeldt CM, Jensen C, Andersen NT, et al. Validation of sick leave measures: self-reported sick leave and sickness benefit data from a Danish national register compared to multiple workplace-registered sick leave spells in a Danish municipality. BMC Public Health 2012;12:661.

35. Dansk Økonomi [Danish Economic Council]. Efterløn [Early retirement]. 2005. http://www.dors.dk/sw1147.asp (accessed 8 Oct 2013) 